\title{
Oral health and tobacco research in the Eastern Mediterranean Region in relation to the Framework Convention on Tobacco Control: a scoping review
}

Maha El Tantawi, ${ }^{1}$ Passent Ellakany, ${ }^{2}$ Nourhan M. Aly ${ }^{1}$ and Hana Moussa ${ }^{1}$

${ }^{1}$ Department of Pediatric Dentistry and Dental Public Health, Faculty of Dentistry, Alexandria University, Alexandria, Egypt. ${ }^{2}$ Department of Substitutive Dental Sciences, College of Dentistry, Imam Abdulrahman Bin Faisal University, Dammam, Saudi Arabia. (Correspondence to: Maha El Tantawi: maha_tantawy@hotmail.com).

\begin{abstract}
Background: Tobacco use is associated with oral diseases. Evaluating research on tobacco use and oral health can provide insight into the prevailing situation and help engage dental personnel in tackling the tobacco problem.

Aims: This study aimed to map knowledge gaps on tobacco and oral health research in the Eastern Mediterranean Region based on four articles of the Framework Convention on Tobacco Control (FCTC). These were: article 12 - use of communication tools to promote tobacco education and awareness; article 14 - promotion of tobacco cessation; article 20 - exchange of information on determinants and outcomes of tobacco use; and article 22 - international cooperation to transfer expertise to strengthen national tobacco control strategies.

Methods: A scoping review was conducted that included publications on tobacco use and oral health in the Region. PubMed, Scopus, Web of Science, Google Scholar and Proquest theses were searched. Information extracted included: country, study type, whether more than one country was included and whether the publication addressed FCTC articles 12, 14, 20 or 22 .

Results: In all, 322 publications were included, of which $82.0 \%$ were observational studies and $4.3 \%$ were clinical trials. Most publications (87.9\%) were from the Islamic Republic of Iran, Jordan, Pakistan Saudi Arabia and Yemen. Only 32 (9.9\%) publications included participants from more than one country. Of all the publications, $21.5 \%$ related to article 12 of the FCTC, $4.3 \%$ to article $14,94.7 \%$ to article 20 and $6.5 \%$ article 22 .
\end{abstract}

Conclusions: Research on oral health and tobacco needs to be better aligned with the FCTC articles.

Keywords: tobacco, tobacco use cessation, oral health, dentistry, Eastern Mediterranean Region

Citation: El Tantawi M; Ellakany P; Aly NM; Moussa H. Research on oral health and tobacco use in the Eastern Mediterranean Region in relation to the Framework Convention on Tobacco Control: a scoping review. East Mediterr Health J. 2020;26(1):85-93. https://doi.org/10.26719/2020.26.1.85

Received: 28/02/19; accepted: 31/07/19

Copyright (C) World Health Organization (WHO) 2020. Open Access. Some rights reserved. This work is available under the CC BY-NC-SA 3.o IGO license (https://creativecommons.org/licenses/by-nc-sa/3.o/igo)

\section{Introduction}

Tobacco is associated with many health problems and high mortality rates (1). It is a risk factor for oral diseases including periodontal pockets, alveolar bone loss, tooth mobility, tooth loss and implant failure (2). Studies have shown a higher risk of caries because of lower $\mathrm{pH}$ of saliva, reduced salivary buffering capacity, sugar added to tobacco by manufacturers and high number of lactobacilli and Streptococcus mutans in the mouths of tobacco users $(3,4)$. Tobacco causes mucosal irritation that may progress to oral precancerous and cancerous lesions. The associated heat from tobacco smoking causes mucosal dryness and higher intraoral temperature with a greater risk of oral infections. Other oral effects of tobacco include bad breath (5), staining of teeth, altered taste and nicotinic stomatitis (2). All forms of tobacco are implicated in such health effects including smoked tobacco, such as cigarettes, cigars, and pipes (6), and smokeless tobacco, such as snuff or chewed tobacco (7).

The World Health Organization (WHO) proposed the Framework Convention on Tobacco Control (FCTC) which is a global public health treaty providing a path for governments to control tobacco. The FCTC came into effect in 2005 and as of 2017, 181 countries are party to the convention (8).

The WHO Eastern Mediterranean Region (EMR) comprises 22 countries. Of the WHO regions, the EMR had the highest increase in the number of tobacco users from 2010 to 2015 (9) and this number is expected to further increase by $25 \%$ by $2025(10,11)$. The increase in tobacco use is attributed to the large proportion of young people who are likely to become users if no action is taken. It is also attributed to the growing use of tobacco in women and use of smokeless tobacco and waterpipes (12). The countries of the Eastern Mediterranean Region, except Palestine and Somalia, are FCTC signatories/ parties indicating their political commitment to support the treaty. However, implementation of the FCTC had not progressed in these countries between 2011 and 2015 (13) and this is still likely to be the case.

Dental care personnel can play an important role in controlling tobacco use by identifying its intraoral 
signs earlier than other health care professionals. Therefore, they are in a position to offer preventive care (e.g. cessation advice) (14). The FCTC includes four articles that can be supported by dental care personnel and assessed by dental research. These are: article 12 on use of communication tools to promote education and awareness of tobacco issues; article 14 on promotion of tobacco cessation; article 20 on exchange of information about determinants and outcomes of tobacco use; and article 22 on international cooperation to transfer scientific expertise to strengthen national tobacco control strategies (15). Thus, the FCTC can guide the design, implementation and evaluation of oral health and tobacco research in the Region to maximize its effect on tobacco control.

Evaluating the type, location and progress of dental research conducted in the Eastern Mediterranean Region on tobacco and oral health can help engage dental care personnel in tobacco control, identify countries where research is needed because of a high prevalence of tobacco use and allow countries of the Region to build on each other's successes to control tobacco use. Evaluating research also provides insight into the prevailing situation to enable capacity-building for dental researchers using regional expertise to tackle the tobacco problem.

A scoping review maps research evidence on a broad topic and identifies research gaps. It follows a rigorous method to identify publications, ensure that they fit prespecified criteria and chart items to develop a research map (16). A scoping review was used here to map dental research on tobacco and oral health according to selected FCTC articles and identify knowledge gaps in the 22 countries of the WHO Eastern Mediterranean Region.

\section{Methods}

\section{Study design}

A scoping review methodology, as outlined in the Joanna Briggs Institute manual (17) and the checklist of the Preferred Reporting Items for Systematic reviews and Meta-Analyses extension for scoping review (PRISMA-ScR, Appendix 1, available on online), was used (18).

\section{Research question}

The research question was based on the four FCTC articles relevant to oral health, which were modified to fit the dental context: article 12 - use of communication tools to promote education and awareness of tobacco issues; article 14 - promotion of tobacco cessation; article 20 - exchange of information about determinants and outcomes of tobacco use; and article 22 - international cooperation to transfer scientific expertise to strengthen national tobacco control strategies (15). The research question was: how has the FCTC affected dental research in each and all countries of the Region? We assessed its influence by evaluating research on (i) the effect of tobacco use on oral health and dental treatment, (ii) the knowledge, attitude and practices of dental care personnel about tobacco, (iii) the knowledge, attitude and practices of the general public about tobacco, (iv) tobacco control interventions in the countries and (v) collaborations in tobacco and oral health research through the recruitment of participants from several EMR countries.

\section{Eligibility criteria}

Publications were selected for the study if they included: (i) participants living in at least one country of the Region, (ii) data on tobacco, and (iii) data on oral structures (e.g. tissues and their combinations with prosthetics or restoration), oral conditions, dental care personnel, dental students or dental treatment. Theses available on the Internet were included. There were no language, time, gender or age restrictions. Publications with participants from the Region who were living outside the Region were excluded as were publications by researchers from institutions in the Region that included only participants from outside the Region. Books were excluded.

\section{Information sources}

PubMed, Scopus, Web of Science, Google Scholar and Proquest dissertation and theses databases were searched using search terms covering the three concepts of the inclusion criteria (Appendix 2 includes details of the search strategies, available online). The search was conducted from November to December 2018. Mendeley folders were created for each country. Countries were randomly allocated to our team members to search for publications and the results were saved in the relevant folders. Subsequently, all search results were saved to one Mendeley folder and checked to remove duplicates. A level 1 screening was performed (title and abstract) and level 2 screening (full text) of the remaining publications. These two screening steps were checked by another investigator who had not been involved in the screening and differences were resolved by consensus.

\section{Data charting}

A data charting form was prepared, which was tested on five publications. Twenty-two columns were added, one for each country, so that countries having collaborated in a publication could be captured. Using the final version of the data charting form, each of us independently charted data from the publications assigned to her and further excluded publications that did not fit the inclusion criteria (level 3 screening). A check was done at the end for all entries by another examiner.

The following data for each publication were extracted; (i): publication year, (ii): whether more than one country (from anywhere in the world) was included (yes/ no), (iii) whether more than one country of the Region was included (yes/no), (iv) name of the country of Region included, (v) age of participants (preschool children, 0-5 years; schoolchildren, 6-12 years; adolescents, 13-18 years; young adults, 19-24 year old; adults, 25-44 years; adults, 45-64 years; adults, 65+ years; multiple and unspecified), (vi) study type (letter, case report, case series, cross-sectional, case-control, cohort, clinical trial, systematic review, narrative review, report, in vitro 
study and diagnostic accuracy study) (vii) tobacco type (cigarette, cigar, waterpipe, smokeless tobacco, pipe, e-cigarette, multiple and unspecified), (viii) whether the publication addressed the effect of tobacco on oral health or dental treatment (yes/no); (ix) whether the publication addressed the determinants of tobacco use (yes/no); (x) whether the publication addressed tobacco knowledge, attitudes and practices of the general public (yes/no); (xi) whether the publication addressed tobacco knowledge, attitudes and practices of dental care personnel (yes/no); and (xii) whether the publication addressed the effect of dental interventions on tobacco control (yes/no).

\section{Synthesis of results}

The number of publications was calculated for the charted items for each country of the Region and overall, and compared these numbers with the prevalence of tobacco use in the country (19). Studies were categorized into observational (cross-sectional, case-control and cohort), clinical trials, reviews/reports (narrative review, system- atic review and report) and others (letter, case report, case series, in vitro study and diagnostic accuracy study).

The correlation was assessed between number of publications and the prevalence of tobacco use using the Pearson correlation coefficient.

\section{Results}

Figure 1 shows the flowchart of the selection process of publications for the scoping review. A total of 4041 publications were retrieved. After removing duplicates, 2186 remained. After screening the title/abstract and applying the inclusion criteria at different stages, 322 publications were available for inclusion.

Figure 2 shows the trend in publications addressing oral health and tobacco from 1968 to 2018. Before 2000, fewer than five papers a year were published on oral health and tobacco in all 22 EMR countries. From 2000 publications per year increased except for 2011 where it dropped to only five publications. The greatest number of publications was in 2015 (36 publications, average of 1.6 publications per country).

Figure 1 Flow chart of selection of studies included in the scoping review

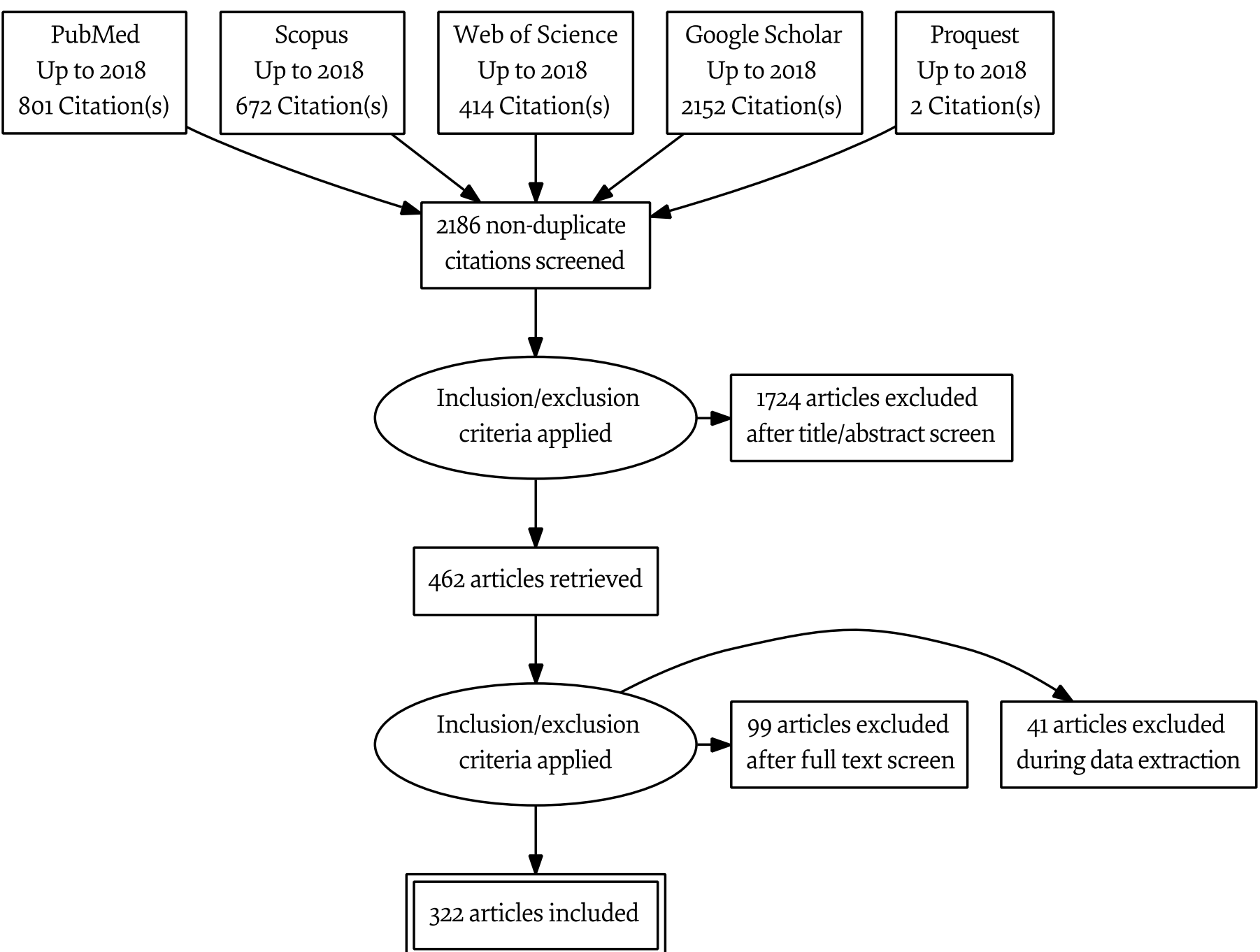




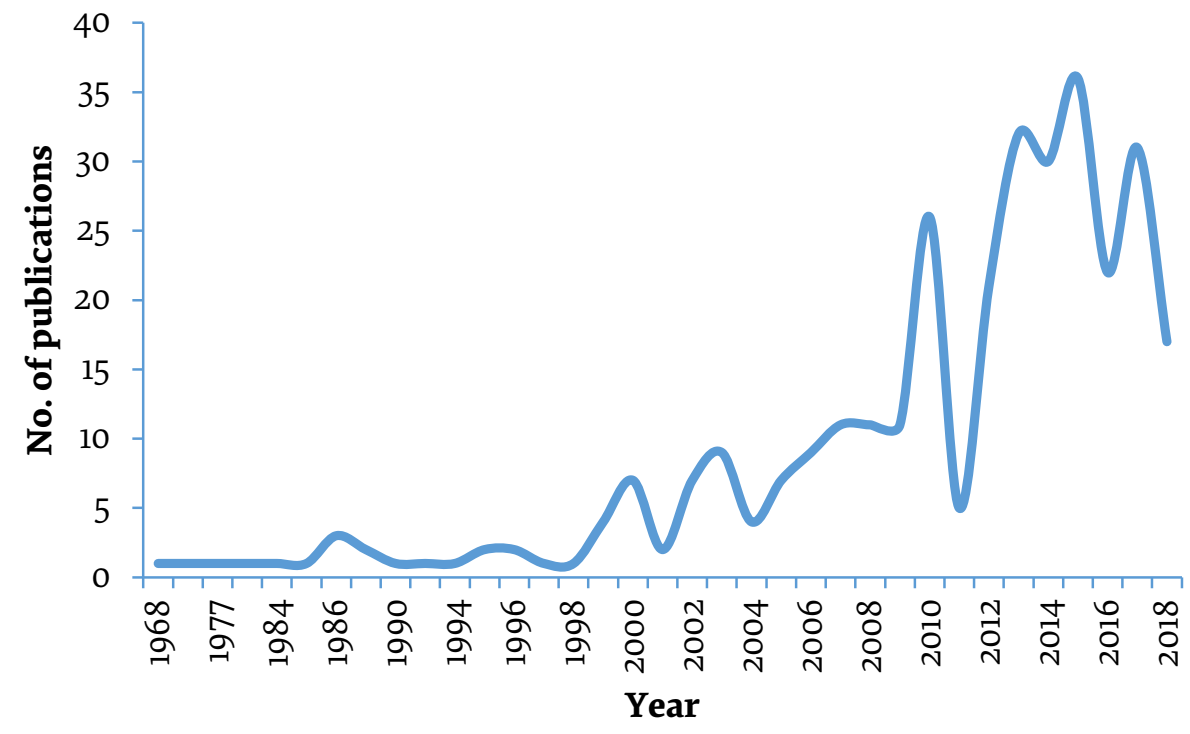

\begin{tabular}{|c|c|c|c|c|c|}
\hline \multirow[t]{2}{*}{ Country $^{a}$} & \multirow{2}{*}{$\begin{array}{c}\text { Prevalence of } \\
\text { tobacco use (19) } \\
\%\end{array}$} & \multirow{2}{*}{$\begin{array}{c}\text { Total } \\
\text { publications } \\
\text { No. }\end{array}$} & \multirow{2}{*}{$\begin{array}{c}\text { Publications } \\
\text { including >1 } \\
\text { country of the } \\
\text { Region } \\
\text { No. (\%) }\end{array}$} & \multirow{2}{*}{$\begin{array}{c}\text { Observational } \\
\text { studies } \\
\\
\text { No. (\%) }\end{array}$} & \multirow{2}{*}{$\begin{array}{l}\text { Clinical trials } \\
\text { No. (\%) }\end{array}$} \\
\hline & & & & & \\
\hline Saudi Arabia & 16 & 79 & $12(15.2)$ & $63(79.8)$ & $5(6.3)$ \\
\hline Pakistan & 19 & 66 & $10(15.2)$ & $46(69.7)$ & 0 \\
\hline Islamic Republic of Iran & 11 & 60 & $9(15.0)$ & $46(76.7)$ & $3(5.0)$ \\
\hline Yemen & 17 & 40 & $12(30.0)$ & $27(67.5)$ & $1(2.5)$ \\
\hline Jordan & - & 38 & $7(18.4)$ & $26(68,4)$ & $3(7.9)$ \\
\hline Sudan & - & 28 & $11(39.3)$ & $19(67.9)$ & 0 \\
\hline Egypt & 25 & 19 & $9(47.4)$ & $7(36.8)$ & $2(10.5)$ \\
\hline Iraq & - & 16 & $6(37.5)$ & $10(62.5)$ & 0 \\
\hline Morocco & 24 & 14 & $7(50)$ & $5(35.7)$ & 0 \\
\hline United Arab Emirates & 29 & 13 & $10(76.9)$ & $4(30.8)$ & $1(7.7)$ \\
\hline Libya & 9 & 11 & $7(63.6)$ & $3(27.3)$ & 0 \\
\hline Tunisia & 33 & 11 & $6(54.5)$ & $4(36.4)$ & 0 \\
\hline Kuwait & 24 & 9 & $5(55.6)$ & $3(33.3)$ & 0 \\
\hline Lebanon & 33 & 9 & $7(77.8)$ & $3(33.3)$ & 0 \\
\hline Syrian Arab Republic & - & 9 & $8(88.9)$ & $1(11.1)$ & 0 \\
\hline Bahrain & 27 & 7 & $6(85.7)$ & $1(14 \cdot 3)$ & 0 \\
\hline Oman & 12 & 7 & $6(85.7)$ & $1(14.3)$ & 0 \\
\hline Palestine & - & 7 & $6(85.7)$ & $1(14.3)$ & 0 \\
\hline Qatar & 22 & 7 & $5(71.4)$ & $2(28.6)$ & 0 \\
\hline Afghanistan & - & 6 & $6(100)$ & 0 & 0 \\
\hline Djibouti & 13 & 4 & $4(100)$ & 0 & 0 \\
\hline Somalia & - & 4 & $4(100)$ & 0 & 0 \\
\hline All & & 322 & $21(6.5)$ & $264(82)$ & $14(4.3)$ \\
\hline
\end{tabular}


Table 1 shows the number of publications on oral health and tobacco of each country. The five countries with the most publications were Saudi Arabia (79 publications), Pakistan (66), Islamic Republic of Iran (60), Yemen (40) and Jordan (38) giving a total of 283 publications $(87.9 \%$ of the 322 publications). Apart from information in four multicountry reviews/reports, no publications were available on Djibouti and Somalia. Lebanon, Tunisia, United Arab Emirates and Bahrain had the highest prevalence of tobacco use (>25\%). The number of publications was negatively correlated with the prevalence of tobacco use but this was not statistically significant (Pearson $r=-0.35, P=0.20$ ).

Of the 322 publications, 32 (9.9\%) included participants from more than one country, 21 (6.5\%) included participants from more than one country of the Region (addressing FCTC article 22) and 301 addressed the situation in one country of the Region only. Four (1.2\%) reviews/reports covered all 22 countries of the Region. In two other publications, data were collected on three countries of the Region and in 12 publications, data were collected on two countries. Excluding the four multicountry reviews/ reports, Saudi Arabia and Yemen had the most publications that included more than one country of the Region (eight publications each) followed by Sudan (seven), Pakistan and UAE (six each), Egypt and Islamic Republic of Iran (five each) and the Syrian Arab Republic (four).

Most publications (82.0\%) reported observational studies (Table 1). Figure 3 shows the study designs of the publications: $58.7 \%$ were cross-sectional studies, $20.2 \%$ were case-control studies and 3.4\% were cohort studies. Only 14 (4.3\%) publications reported clinical trials (Table 1 and Figure 3). Egypt, Jordan and the United Arab Emirates had the highest percentage of clinical trials relative to their total number of publications (> 7.5\%) (Table 1). The 14 clinical trials included participants from Saudi Arabia (five publications), Islamic Republic of Iran (three), Jordan (three), Egypt (two) and United Arab Emirates (one). Most clinical trials were used to investigate interventions to reduce the effect of tobacco on oral health and dental treatment (11 publications); only three of the published clinical trials assessed interventions on tobacco control and interventions to modify the knowledge, attitudes and practices of the general public with regard to tobacco and its effects, harms, use and cessation.

Figure 4 shows that most publications addressed FCTC article 20 (exchange of information on determinants and outcomes of tobacco use), including the effect of tobacco use on oral health and dental treatment (79.5\%) and factors affecting tobacco use (15.2\%). Fewer publications addressed FCTC article 12 (use of communication tools to promote tobacco education and awareness): knowledge, attitudes and practices in the general public (10.6\%) and dental care personnel (10.9\%). Only $4.3 \%$ of the publications focused on interventions to control tobacco use (FCTC article 14).

Most publications (59.0\%) included participants of multiple age groups or unspecified ages (14.9\%). Young adults (9.0\%) and adults (6.5\%) were the two single age groups most frequently studied; only one study (0.3\%) focused on preschool children and another study (0.3\%) on older people. Seven studies (2.2\%) exclusively included adolescents (Appendix 3, available on line).

Most publications addressed multiple (32.3\%) or unspecified types of tobacco (28.6\%). Smokeless tobacco (21.1\%) and cigarettes (13.4\%) were the most common types of tobacco examined where only one tobacco product was

\section{Figure 3 Study designs of the publications on tobacco use and oral health in the Eastern Mediterranean Region}

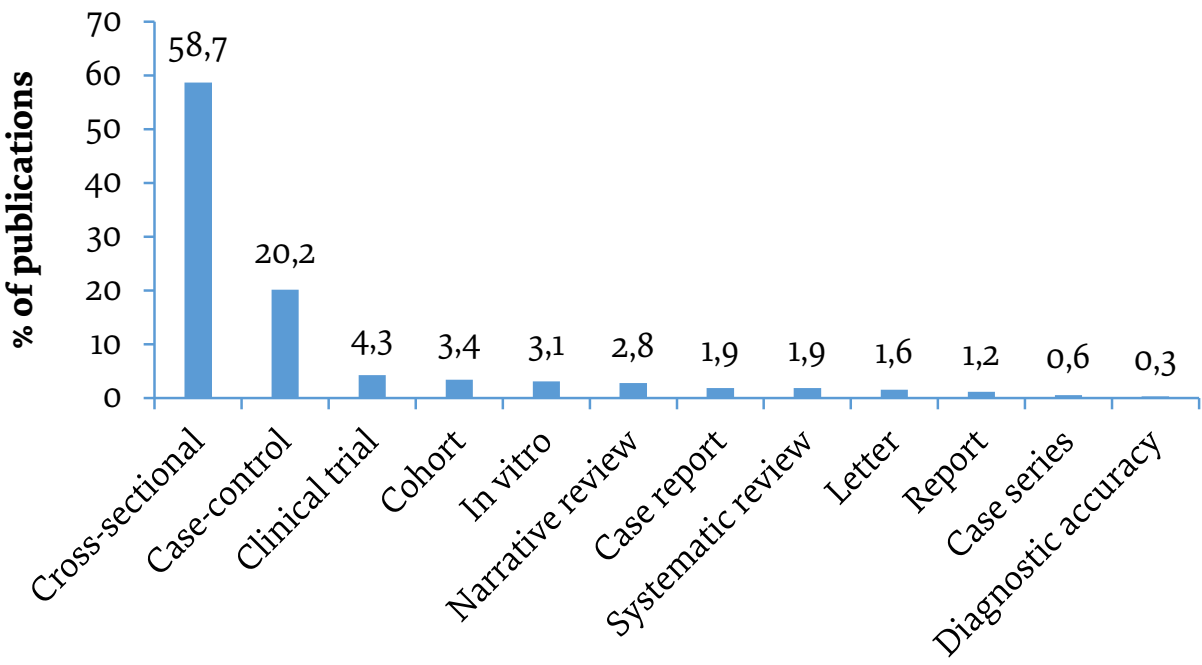

Study design 
included; publications that examined only waterpipe use were less common (3.7\%).

\section{Discussion}

This study shows that countries of the WHO EMR with the highest prevalence of tobacco use had fewer publications on tobacco use and oral health than other countries of the Region. In addition, most of the publications on tobacco use and oral health were from a small number of countries. Furthermore, few publications addressed tobacco use and oral health in more than one country of the Region. Despite the increase in tobacco and oral health literature in the Region, most publications were aligned with only one FCTC article and few studies directly dealt with tobacco cessation. Most publications were observational studies with only a small number of clinical trials. Few studies addressed young age groups when tobacco use may become established.

The findings showed an increase in the number publications on tobacco and oral health in the Region over time but overall the number of publications was limited. The increase may reflect a greater global focus on tobacco problems after the FCTC. The decrease in publications in 2011 may be attributed to war and political unrest in Egypt, Libya and Syrian Arab Republic and is an indication of how circumstances may affect research. The findings on an overall small amount of health research in the Region compared to global levels concur with other studies that showed a marked increase in research publications after 2000 (20) and an increase after a drop in 2011 (21).

More publications were found with participants from countries within and outside the Region than publications that recruited participants exclusively from several countries of the Region. This finding suggests collaboration between countries of the Region and the world is greater than collaboration within the Region. Other research has also reported greater collaboration in health research between countries of the Region and European and North American countries than between countries of the Region (20). Another study reported that $61 \%$ of publications on noncommunicable diseases in the Region were one-country studies and 30\% involved regional collaboration (21).

Most of the publications on tobacco and oral health in our review were from Islamic Republic of Iran, Jordan, Pakistan, Saudi Arabia and Yemen. The findings differ from other research that reported that Egypt and Pakistan produced the most health research (20). This difference may be attributed to differences in the research areas and specialties examined. Tobacco and oral health research was also looked at but other countries of the Region may conduct a greater amount of research on the other fields.

Few of the publications in this study reported clinical trials or systematic reviews; of the clinical trials reported, two thirds were from the Islamic Republic of Iran and Saudi Arabia. This partly agrees with a previous study that showed that the greatest increase in clinical trial registration in countries of the Region in the past decade was in the Islamic Republic of Iran (22). Clinical trials and systematic reviews provide the highest level of research evidence to inform clinical decision-making and policy setting. The small number in our study suggests that the

Figure 4 Areas of tobacco use and oral health addressed in the publications in the Eastern Mediterranean Region and the FCTC articles they relate to (blue bars - article 20, orange bar - article 14 and green bars - article 12)

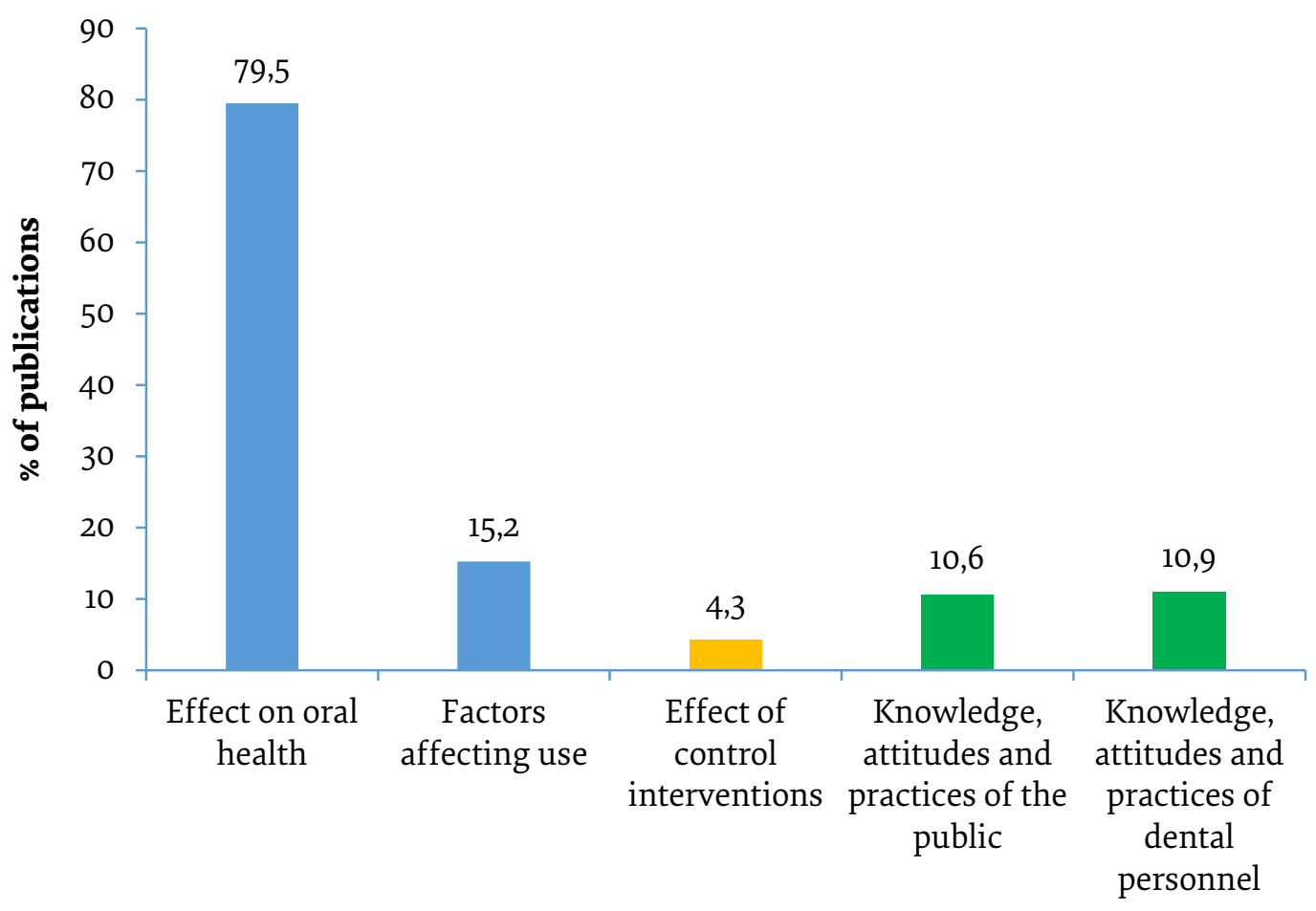


availability of robust evidence to inform clinical practice and policy is limited.

The number of publications addressing different articles of the FCTC varied. While a large number of publications related to an FCTC article does not necessarily mean that this article has been successfully implemented, it gives an indication of the focus on FCTC articles in a country in general and in the health research community including the dentistry community. Our study partly agrees with previous research showing global variation in the progress toward implementing the FCTC in its first 10 years. Rapid progress was made in implementing article 12 , while progress was slower for articles 14 and 20; the least progress made was in implementing article 22 (15). Another study that assessed progress in implementing article 14 surveyed key stakeholders in 142 countries and showed better implementation in higher-income countries (23). Research suggests that tobacco cessation services by dentists may be as effective as those provided by other health professionals $(24,25)$, and that tobacco control services provided by dentists can be improved with training and have a positive effect on patients who smoke even if they are not paid for this as a patient care service $(26,27)$. Research on tobacco cessation in a dental context in countries of the Region would provide guidance on designing tobacco control interventions to be implemented by dental care personnel.

The limited amount of research on oral health and tobacco control in the Region may be because of challenges in conducting heath research in general (20). These challenges include limited human resources, financial constraints and problems of data availability because of the health system structure (most health care systems in the Region include no or limited surveillance, so risk factors and disease outcomes are not linked in large datasets that enable research. Similarly, patient records are often not complete). Such challenges are made worse by inadequate research strategies in many countries of the Region that limit the ability of research to respond to local health conditions. Another explanation for the small number of publications on oral health and tobacco control in the Region may be the limited interest and training of dental researchers to explore non-dental solutions to tobacco problems, including pharmacological and behavioural therapies.

This review has some limitations. First, most of the grey literature from the countries of the Region was not included, such as theses or papers published in regional journals, because it is generally not retrievable by search engines. This could have resulted in an underestimation of publications on tobacco and oral health and highlights one of the main challenges facing research in the Region. Second, the findings of the studies were not assessed whether they were translated to policies or improvement in clinical practices. This is an area of research that is needed.

Nonetheless, this scoping review is the first to map the status of research on oral health and tobacco in the Region. Gaps were identified in research including the need for multicountry clinical trials assessing the effect of interventions by dentistry personnel to control tobacco, especially in countries of the Region where tobacco use is most prevalent.

Funding: None.

Competing interests: None declared.

\section{Recherche sur le tabagisme et la santé bucco-dentaire dans la Région de la Méditerranée orientale en lien avec la Convention-cadre de l'OMS pour la lutte antitabac : étude exploratoire}

\section{Résumé}

Contexte : Le tabagisme est un facteur associé aux maladies bucco-dentaires. L'évaluation de la recherche menée sur le tabagisme et la santé bucco-dentaire peut fournir des indications sur la situation en cours et contribuer à impliquer le personnel de santé bucco-dentaire dans la lutte antitabac.

Objectifs : La présente étude avait pour objectif d'identifier les lacunes en matière de connaissances dans la recherche menée sur le tabagisme et la santé bucco-dentaire dans la Région de la Méditerranée orientale. Elle s'appuie sur quatre articles de la Convention-cadre pour la lutte antitabac : l'article 12 concernant l'utilisation des outils de communication disponibles pour promouvoir l'éducation et la sensibilisation du public à la lutte antitabac; l'article 14 concernant la promotion du sevrage tabagique; l'article 20 concernant l'échange d'informations sur les déterminants et les conséquences de la consommation de tabac; et l'article 22 concernant la coopération internationale pour le transfert des compétences permettant de renforcer les stratégies nationales de lutte antitabac.

Méthodes : L'étude exploratoire réalisée s'est penchée notamment sur les publications relative au tabagisme et à la santé bucco-dentaire dans la Région. Les thèses publiées dans PubMed, Scopus, Web of Science, Google Scholar et Proquest ont été passées en revue. Les informations extraites incluaient: le pays, le type d'étude, le nombre de pays étudiés (un ou plusieurs) et la référence éventuelle aux articles 12, 14, 20 ou 22 de ladite Convention-cadre de l'OMS dans chaque publication. 
Résultats : En tout, 322 publications ont été incluses, dont $82 \%$ d'études d'observation et 4,3\% d'essais cliniques. La plupart des publications (87,9\%) provenaient d'Arabie saoudite, de la République islamique d'Iran, de Jordanie, du Pakistan et du Yémen. Seules 32 publications (9,9\%) incluaient des participants de plusieurs pays. Parmi toutes les publications, $21,5 \%$ étaient liées à l'article 12 de la Convention-cadre de l'OMS pour la lutte antitabac, 4,3\% à l'article 14, 94,7\% à l'article 20 et $6,5 \%$ à l'article 22 .

Conclusions : La recherche sur le tabagisme et la santé bucco-dentaire doit être mieux alignée sur les articles de la Convention-cadre OMS pour la lutte antitabac.

$$
\text { مهحا الطنطاوي، بسنم وتعاطي التبغ في إقليم شرق المتوسط فيها يتعلق بالاتفاقية الإطارية بشأن مكافحة التبغ: مراجعة نطاقية }
$$

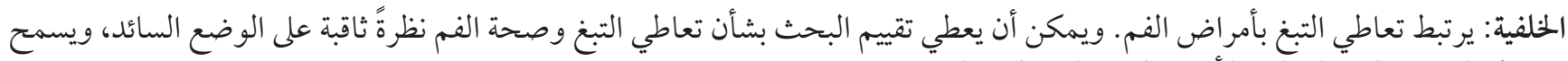

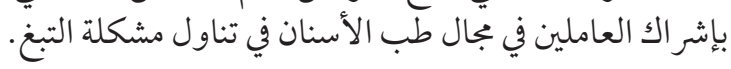

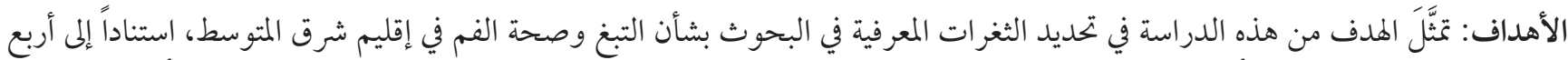

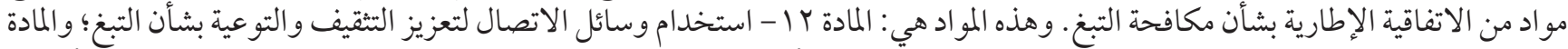

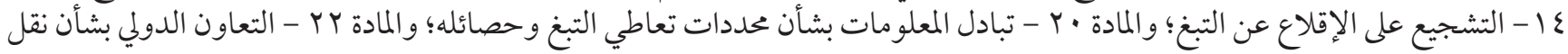

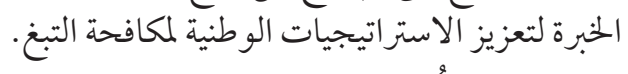

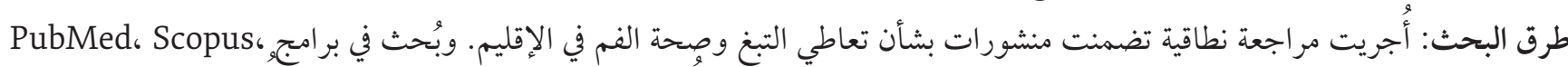
. Web of Science،Google Scholar، Proquest تناوَل المنشور المواد r ا أو ع أو · r أو r r من الاتفاقية الإطارية بشأن مكافحة التبغ.

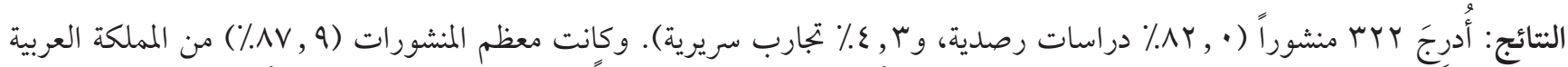

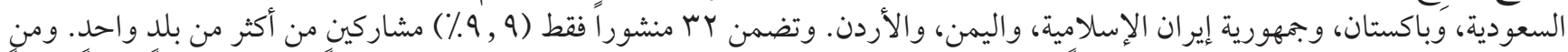

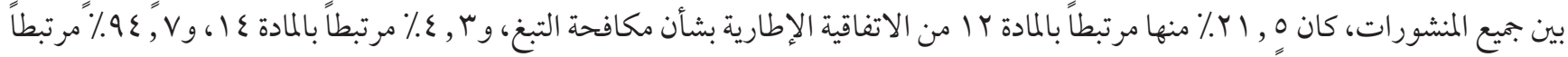

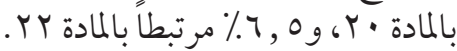
الاستنتاجات: من الضروري مو اءمة البحوث بشأن صحة الفم والتبغ بصورةٍ أفضل مع مو اد الاتفاقية الإطارية بشأن مكافحة التبخ.

\section{References}

1. Etemadi A, Khademi H, Kamangar F, Freedman ND, Abnet CC, Brennan P, et al. Hazards of cigarettes, smokeless tobacco and waterpipe in a Middle Eastern population: a cohort study of 50000 individuals from Iran. Tob Control. 2017;26(6):674-82. https:// doi.org/10.1136/tobaccocontrol-2016-053245

2. Warnakulasuriya S, Dietrich T, Bornstein MM, Peidró EC, Preshaw PM, Walter C, et al. Oral health risks of tobacco use and effects of cessation. Int Dent J. 2010;60(1):7-30. https://doi.org/10.1922/IDJ_2532Warnakulasuriya24

3. Huang R, Li M, Gregory RL. Effect of nicotine on growth and metabolism of Streptococcus mutans. Eur J Oral Sci. 2012;120(4):319-25. https://doi.org/10.1111/j.1600-0722.2012.00971.x

4. Vellappally S, Fiala Z, Smejkalová J, Jacob V, Shriharsha P. Influence of tobacco use in dental caries development. Cent Eur J Public Health. 2007;15(3):116-21.

5. Bornstein MM, Kislig K, Hoti BB, Seemann R, Lussi A. Prevalence of halitosis in the population of the city of Bern, Switzerland. Eur J Oral Sci. 2009;117(3):261-7. https://doi.org/10.1111/j.1600-0722.2009.00630.x

6. West R. Tobacco smoking: health impact, prevalence, correlates and interventions. Psychol Health. 2017;32(8):1018-36. https://doi. org/10.1080/08870446.2017.1325890

7. Siddiqi K, Shah S, Abbas SM, Vidyasagaran A, Jawad M, Dogar O, et al. Global burden of disease due to smokeless tobacco consumption in adults: analysis of data from 113 countries. BMC Med. 2015;13(1):194. https://doi.org/10.1186/s12916-015-0424-2

8. Framework Convention on Tobacco Control. Geneva: World Health Organization; 2003 (https://www.who.int/tobacco/framework/WHO_FCTC_english.pdf, accessed 7 October 2019).

9. WHO global report on trends in prevalence of tobacco smoking 2015. Geneva: World Health Organization; 2015 (https://apps.who. int/iris/bitstream/handle/10665/156262/9789241564922_eng.pdf?sequence=1, accessed 24 February 2019).

10. WHO global report on trends in prevalence of tobacco smoking 2000-2025. Second edition. Geneva: World Health Organization; 2018. (https://apps.who.int/iris/bitstream/handle/10665/272694/9789241514170-eng.pdf?ua=1, accessed 24 February 2019). 
11. Heydari G, Zaatari G, Al-Lawati JA, El-Awa F, Fouad H. MPOWER, needs and challenges: trends in the implementation of the WHO FCTC in the Eastern Mediterranean Region. East Mediterr Health J. 2018;24(1):63-71.

12. Ali AYM, Safwat T, Onyemelukwe G, Otaibi MA Al, Amir AA, Nawas YN, et al. Smoking prevention and cessation in the Africa and Middle East Region: A consensus draft guideline for healthcare providers - executive summary. Respiration. 2012;83(5):42332. https://doi.org/10.1159/000337726

13. Heydari G, EbnAhmady A, Lando HA, Chamyani F, Masjedi M, Shadmehr MB, et al. Third study on WHO MPOWER tobacco control scores in Eastern Mediterranean countries 2011-2015. East Mediterr Health J. 2017;23(9):598-603.

14. Emanuel AS, Parish A, Logan HL, Dodd VJ, Zheng D, Guo Y. Dental visits mediate the impact of smoking on oral health. Am J Health Behav. 2018;42(1):59-68. https://doi.org/10.5993/AJHB.42.1.6

15. Chung-Hall J, Craig L, Gravely S, Sansone N, Fong GT. Impact of the WHO FCTC over the first decade: a global evidence review prepared for the Impact Assessment Expert Group. Tob Control. 2018;28(Suppl 2):s119-s128. https://doi.org/10.1136/tobaccocontrol-2018-054389

16. Tricco AC, Lillie E, Zarin W, O'Brien K, Colquhoun H, Kastner M, et al. A scoping review on the conduct and reporting of scoping reviews. BMC Med Res Methodol. 2016;16(1):15. https://doi.org/10.1186/s12874-016-0116-4

17. The Joanna Briggs Institute reviewers' manual 2015. Methodology for JBI scoping reviews. Adelaide: The Joanna Briggs Institute; 2015. (https://nursing.lsuhsc.edu/JBI/docs/ReviewersManuals/Scoping-pdf, accessed 16 October 2019).

18. Tricco AC, Lillie E, Zarin W, O’Brien KK, Colquhoun H, Levac D, et al. PRISMA extension for scoping reviews (PRISMA-ScR): checklist and explanation. Ann Intern Med. 2018;169(7):467-73. https://doi.org/10.7326/M18-0850

19. Noncommunicable diseases country profiles 2018. World Health Organization; 2018. (https://www.who.int/nmh/countries/en/, accessed 7 October 2019)

20. Ismail SA, McDonald A, Dubois E, Aljohani FG, Coutts AP, Majeed A, et al. Assessing the state of health research in the Eastern Mediterranean Region. J R Soc Med. 2013;106(6):224-33. https://doi.org/10.1258/jrsm.2012.120240

21. Akkawi A, Noubani A, Jamali S, Lotfi T. Non-communicable diseases in the Eastern Mediterranean Region: an overview of reviews in the Arab Region: the case of non-communicable diseases. Beirut; 2017 (http://website.aub.edu.lb/fhs/fhs_home/Documents/ephd-research/alaa.pdf, accessed 7 October 2019).

22. Al-Gasseer N, Shideed O. Clinical trial registration in the Eastern Mediterranean region: a luxury or a necessity? East Mediterr Health J. 2012;18(2):108-11. https://doi.org/10.1177/0022034509350867

23. Nilan K, Raw M, McKeever TM, Murray RL, McNeill A. Progress in implementation of WHO FCTC Article 14 and its guidelines: a survey of tobacco dependence treatment provision in 142 countries. Addiction. 2017;112(11):2023-31. https://doi.org/10.1111/ add. 13903

24. Hanioka T, Ojima M, Tanaka H, Naito M, Hamajima N, Matsuse R. Intensive smoking-cessation intervention in the dental setting. J Dent Res. 2010;89(1):66-70. https://doi.org/10.1177/0022034509350867

25. Nohlert E, Tegelberg Å, Tillgren P, Johansson P, Rosenblad A, Helgason ÁR. Comparison of a high and a low intensity smoking cessation intervention in a dentistry setting in Sweden - a randomized trial. BMC Public Health. BioMed Central; 2009;9(1):121. https://doi.org/10.1186/1471-2458-9-121

26. Walsh MM, Belek M, Prakash P, Grimes B, Heckman B, Kaufman N, et al. The effect of training on the use of tobacco-use cessation guidelines in dental settings. J Am Dent Assoc. 2012;143(6):602-13. https://doi.org/10.14219/jada.archive.2012.0239

27. Amemori M, Virtanen J, Korhonen T, Kinnunen TH, Murtomaa H. Impact of educational intervention on implementation of tobacco counselling among oral health professionals: a cluster-randomized community trial. Community Dent Oral Epidemiol. 2013;41(2):120-9. https://doi.org/10.1111/j.1600-0528.2012.00743.x 